\title{
Aspirin DL-Lysine
}

National Cancer Institute

\section{Source}

National Cancer Institute. Aspirin DL-Lysine. NCI Thesaurus. Code C91032.

The lysine salt form of acetylsalicylic acid, a nonsteroidal anti-inflammatory drug (NSAID) with analgesic, antipyretic and anti-inflammatory activities. Like other NSAIDs, aspirin DLlysine inhibits the activity of cyclooxygenase I and II, resulting in decreased formation of prostaglandins (PGs) and thromboxanes precursors. This leads to decreased PG synthesis by PG synthase. This agent also causes a decrease in the formation of thromboxane A2 synthesis by thromboxane synthase, thereby inhibiting platelet aggregation. 